\title{
Mitigación y biorremediación de suelos contaminados por el derrame de combustible diésel 2 en la Quebrada del Toro, Camaná, 2009
}

\author{
Mitigation and bioremediation of soils contaminated by the spill of diesel 2 fuel in the Valley \\ of the Bull, Camaná, 2009
}

Jose Miguel Rodríguez Bazan,*

http://dx.doi.org/10.21503/CienciayDesarrollo.2009.v10.03

\section{RESUMEN}

El derrame de combustible es considerado uno de los accidentes ambientales más difíciles de mitigar o remediar. Asimismo, estos tipos de derrames se están volviendo más frecuentes debido a diversos factores, entre los cuales se halla el mal estado de las vías de circulación.

En el mes de mayo de 2009, un vehículo cisterna que transportaba 9000 galones de diesel (D2), que transitaba por la Quebrada del Toro, rumbo a la provincia de Camaná, se despistó y colisionó con el cerro en la parte izquierda de la carretera, resultando en la rotura del tanque cisterna y consecuentemente en el derrame de los 9000 galones de combustible. Esto ocasionó la contaminación de los suelos del talud adyacente a la carretera. Parte de ese fluido discurrió pendiente abajo por una de las bermas del lado izquierdo de la carretera.

Se define como biorremediación a cualquier proceso que utilice microorganismos, hongos, plantas o enzimas derivadas de ellos para retornar un medio ambiente alterado por contaminantes a su condición natural.

Las bacterias utilizadas en este trabajo son llamadas microorganismos eficientes (EM). Son provenientes de Japón y trabajan en una simbiosis compuesta por más de 80 tipos de microorganismos de origen natural, entre los cuales destacan tres:

- Bacterias acidolácticas.

- $\quad$ Bacterias fototrópicas.

- Levaduras.

Activación de los microorganismos. Los microorganismos eficientes (EM) se encuentran en estado de latencia, por lo que se necesita realizar su activación 96 horas antes de su primera aplicación.

Aplicación y aireación. Después de la activación de las bacterias, se procedió a realizar la incorporación de los microorganismos a la tierra contaminada por derrame del hidrocarburo diesel 2. Primero, se las colocó en pilas, antes de dar inicio al tratamiento de biorremediación.

Uso final del material contaminado. Después de que el material perdió todas las características contaminantes del hidrocarburo, se hizo entrega del mismo a la municipalidad provincial de Camaná, la que reutilizará este material en los parques y jardines para aprovechar su alto contenido de nutrientes obtenidos por la actividad bacteriana.

*Alumno de la Escuela Académico-Profesional de Ingeniería Ambiental de la filial Arequipa. 


\section{ABSTRACT}

Diesel spilling is considerate one of the most difficult accidents to mitigate or repair. In like manner, these kinds of spilling are happening frequently due to different reasons, principally the bad condition of the roads.

In May 2009, one vehicle with 9000 gallons of petro diesel on road to Camana, crashed with left hill of the road, broken the tank and spilling the 9000 gallons of diesel.

This fact contaminated the adjacent ground of the zone, a little of this fluid flowed through the left side of the road.

Bio remediation is defined like any process that uses microorganism, fungus, plants or derived enzymes of them to return a changed environmental to a natural condition.

The bacterium used in this work are called efficient microorganism (EM). They come from Japan and they work together through 80 kinds of natural microorganism, where detail three:

- $\quad$ Lactic acid

- $\quad$ Phototropic

- $\quad$ Yeast or leaven

Activation of the microorganism. Effective Microorganism (EM), are in latency condition and they need to be activated 96 hours before the first application.

Application and Aeration. After microorganism activation, they were incorporated to the contaminated ground which was collocated in pillars, in this point stars the bio remediation.

Final use of contaminated material. After the material lost all the contaminated characteristics of the hydrocarbon, it delivered to the Camana's municipally for the use in yards and parks because this ground contains a lot nutrient for the microorganism activity.

\section{INTRODUCCIÓN}

\section{Descripción de la problemática}

El gasóleo, también denominado gasoil o diésel, es un líquido de color blancuzco o verdoso, con una densidad de $850 \mathrm{~kg} / \mathrm{m}^{3}\left(0,850 \mathrm{~g} / \mathrm{cm}^{3}\right)$, compuesto fundamentalmente por parafinas $\mathrm{y}$ utilizado principalmente como combustible en motores diésel y en calefacción. Cuando es obtenido de la destilación del petróleo, se denomina petrodiésel, y cuando es obtenido a partir de aceites vegetales se denomina biodiésel.

El transporte de mercancías en el país y en la mayor parte del mundo constituye un elemento estratégico e indispensable del proceso de desarrollo nacional desde el punto de vista económico. El transporte influye en la determinación de los costos de producción de bienes y servicios; además, es un factor esencial en el desarrollo de la industria, pero durante estas operaciones de transporte siempre existen riesgos de accidentes, como los derrames de combustible, que, ya sea por fallas mecánicas o por fallas humanas, generan alteraciones en el medio ambiente. Los impactos, aunque pueden no tener efectos muy drásticos, en ocasiones son muy severos.

Por eso, hoy en día los derrames de hidrocarburos y demás sustancias químicas se consideran emergencias ambientales debido a los riesgos que se generan para la salud humana y para los recursos naturales.

En el mes de mayo de 2009, un vehículo cisterna que transportaba 9000 galones de diesel 2 por la Quebrada del Toro, rumbo a la provincia 
de Camaná, se despistó y colisionó con el cerro en la parte izquierda de la carretera, resultando en la rotura del cisterna y, consecuentemente, en el derrame de los 9000 galones de combustible.

Este accidente ocasionó la contaminación de los suelos del talud adyacente a la carretera. Parte de este fluido discurrió pendiente abajo por una de las bermas del lado izquierdo de la carretera.

Una manera de evitar esto es que cada empresa transportadora de combustible cuente con un plan de contingencia, el cual deberá ser aplicado inmediatamente en este tipo de accidentes.

Los planes de contingencia establecen procedimientos para facilitar una respuesta segura y eficaz ante incidencias laborales que puedan presentarse durante el transporte hacia distintas áreas o durante las operaciones productivas.

El procedimiento de comunicación de contingencia debe estar incluido como una de las principales medidas en el plan de contingencias de la empresa, con la finalidad de designar personas responsables para actuar en casos de derrames o de otras emergencias. Estas personas deberán hacer los requerimientos de control y reportes, así como proporcionar capacitación a todos los trabajadores en lo que respecta a prevención de derrames y emergencias.

Como parte de los procedimientos de comunicación ante una contingencia, está la acción de designar en el lugar a un coordinador que no solamente informe o reporte acerca del accidente, sino que será el responsable de proporcionar asistencia técnica y coordinar la respuesta ante casos de derrame o casos de emergencia. También será el encargado de garantizar que se implementen los procedimientos del plan de contingencia.

Producido un accidente de derrame, se produce el primer contacto de respuestas. El coordinador dirige los recursos y los equipos de respues- ta a utilizar. Luego del incidente, se hará reportes a fin de documentar la siguiente información:

- Nombre del informante.

- Lugar del accidente.

- Fecha y hora aproximada en que se produjo el accidente.

- Característica del accidente.

- Posibles causas del accidente.

- Magnitud del accidente.

- Medio afectado (suelo, agua, aire).

- Cantidad de material derramado.

- Acciones tomadas para contener, recuperar y eliminar el material derramado.

- Evaluación de daños.

- Tratamiento de los daños.

- Entidades que participan en el plan de Contingencia.

- Equipo mínimo para contingencias.

\section{Plan de Comunicación}

\section{Primera persona o coordinador del lugar:}

- Iniciar las acciones de respuesta.

- Comunicarse inmediatamente con las instituciones de ayuda, como son:

1. Hospitales

2. Policía

3. Bomberos

4. Defensa civil

5. Municipalidades

6. Ministerio de Energía y Minas

- Proporcionar los números telefónicos para su rápida ubicación.

- Capacitar a la persona encargada de la respuesta ante emergencias y a los demás trabajadores para tener una cobertura de respuestas a emergencias durante todas las horas laborables.

- Instruir a todo trabajador que descubra un caso de derrame o emergencia para reportar inmediatamente el evento al coordinador en- 
cargado de las contingencias.

- Coordinar con las instituciones (principalmente la Policía Nacional, bomberos, centros de salud) para la realización de simulacros, de modo que, llegado el momento, la comunicación se realice de manera inmediata.

\section{Segunda persona o personal de cuadrilla}

Trata con el coordinador acerca de:

- Los impactos al medio ambiente por el derrame o accidente.

- Las acciones de contención y recuperación que deben desarrollar los demás trabajadores, y cuál de ellas es la más apropiada.

- La evaluación del informe preliminar del accidente o desastre.

- Las actividades de contención, recuperación, limpieza y restauración.

El diésel 2 proviene de un proceso de refinación que parte del crudo de petróleo, y tras el cual van dejando una serie de subproductos que son usados luego para distintos fines, como la fabricación de fertilizantes, cosméticos, aceites, etc. En la figura 1 se muestra un proceso básico de refinación.

El contenido de parafinados, grasas y aceites del diésel afecta gravemente al ambiente, formando en el lugar del siniestro una capa grasosa que daña la flora y la fauna.

\section{Características de la zona de influencia}

\section{Ubicación}

La zona de derrame del hidrocarburo corresponde a la Panamericana Sur, en la ruta Arequipa - Camana, km 863, Quebrada del Toro (foto $\mathrm{N}^{\circ}$ 1, Anexo 2).

\section{Características geográficas de la zona de impacto}

La zona de impacto se ubica en el $\mathrm{km} 863$, aproximadamente a $25 \mathrm{~km}$ de la ciudad de Camana, a una altitud de 569 m.s.n.m.

La Quebrada del Toro se encuentra dentro de la unidad geomorfológica denominada Cordillera de la Costa. Tiene una dirección norte-sur por donde se ha desarrollado la Carretera Panamericana Sur. Presenta una alta pendiente y en

Figura 1. Proceso de obtención del petrodiésel

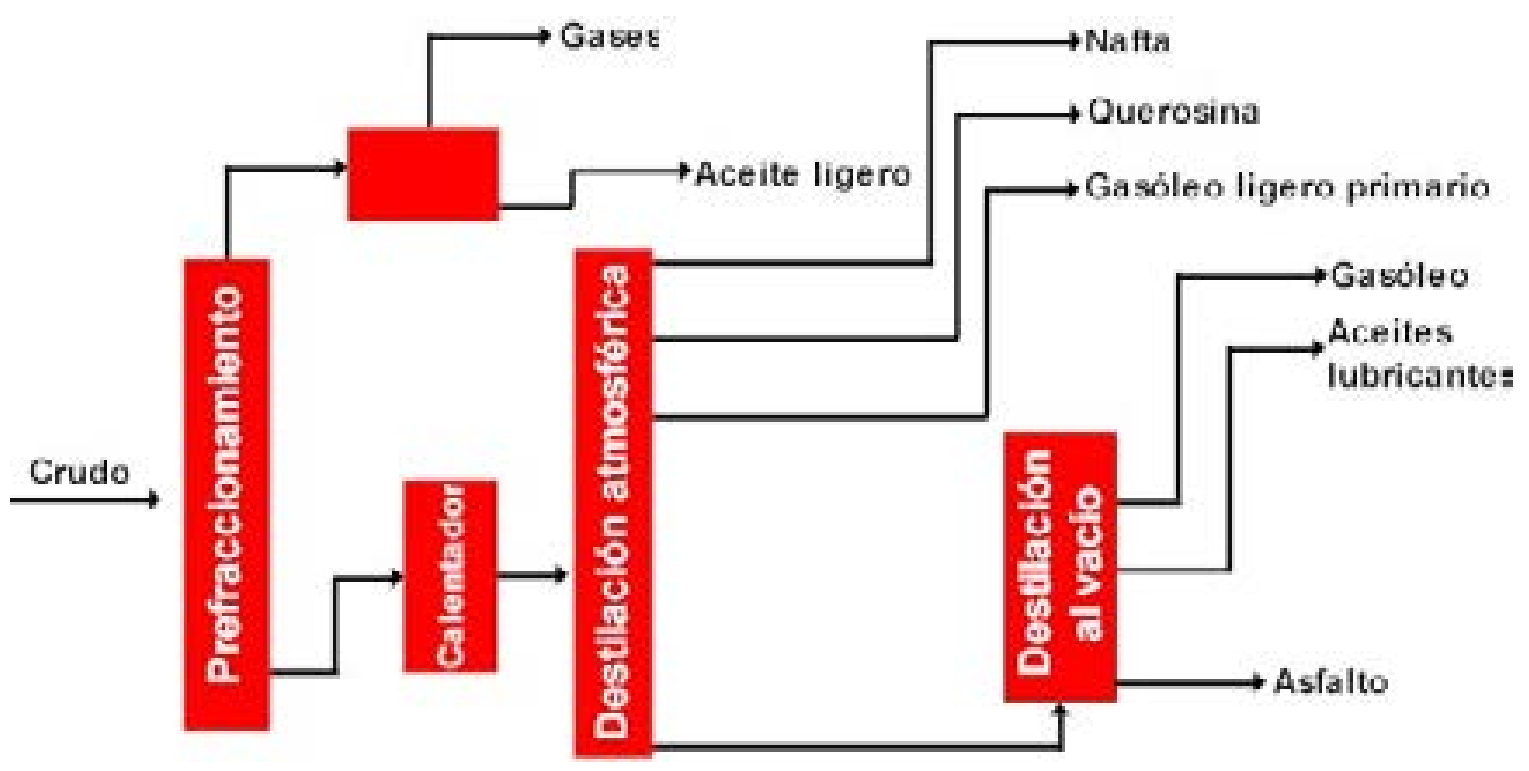


Cuadro 1. Coordenadas

\begin{tabular}{|c|c|c|}
\hline Punto & Cuadrante & $\begin{array}{c}\text { Ubicación } \\
\text { (Coordenadas } \\
\text { UTM) }\end{array}$ \\
\hline 001 & $18 \mathrm{~K}$ & $\begin{array}{c}0753074 \\
8166396\end{array}$ \\
\hline 002 & $18 \mathrm{~K}$ & 0753051 \\
& & 8166391 \\
\hline 003 & $18 \mathrm{~K}$ & 0753050 \\
004 & $18 \mathrm{~K}$ & 07633060 \\
& & 8166383 \\
\hline \multirow{2}{*}{005} & $18 \mathrm{~K}$ & 0753064 \\
& & 8166356 \\
\hline \multirow{2}{*}{006} & $18 \mathrm{~K}$ & 0753097 \\
\hline
\end{tabular}

muchos de sus tramos se han desarrollado curvas de mucha peligrosidad, siguiendo la topografía natural de la zona. Una de las de mayor peligro es la Curva del Diablo, nombre con que se conoce el lugar del accidente.

\section{Características geológicas de la zona}

La zona de impacto está constituida geológicamente por rocas ígneas intrusivas de edad precámbrica a del paleozoico inferior, cuya edad aproximada es de 440 millones de años. Forma parte del complejo basal de la costa, y la roca ígnea identificada es conocida con el nombre de granito rojo.

Sobre estas rocas ígneas se han identificado las rocas sedimentarias de la formación Camaná, formada por capas subhorizontales de arenisca, arcósicas y arcillas de diferentes colores, los mismos que varían entre crema y gris. Son capas intercaladas con arenisca coquinera y lentes de conglomerados con abundante microfauna y macrofauna. Esto muestra el carácter marino de la formación Camaná, y que toda esta región estuvo bajo el mar en el pasado (oligoceno superior a mioceno inferior).

\section{Características del granito rojo}

El granito rojo de Camaná es parte del complejo basal de la costa, y está expuesto en la zona del siniestro. Macroscópicamente, presenta las siguientes características: su color varía entre rosado y rojizo, y presenta una textura macrogranular, holocristalina. Está compuesto de ortosa o microclina de color rosado en grandes cristales simples y calcados, cuyo diámetro varía desde algunos milímetros hasta más de $3 \mathrm{~cm}$. Se observan también cristales de cuarzo con dimensiones de hasta de $5 \mathrm{~mm}$, y en menor proporción se presenta biotita y horblenda.

Cuadro 2. Análisis microscópico del granito rojo

\begin{tabular}{|c|c|}
\hline Ortosa & $62,9 \%$ \\
\hline Cuarzo & $19,8 \%$ \\
\hline Oligoclasa & $9,6 \%$ \\
\hline Biotita & $5,8 \%$ \\
\hline Otros & $1,9 \%$ \\
\hline
\end{tabular}

\section{Características de la Quebrada del Toro}

La Quebrada del Toro es una de las quebradas que cortan transversalmente la Cadena Costera siguiendo una dirección norte-sur, y que llegan directamente a la línea de la costa. Es parte de un drenaje semiparalelo que se desarrolla en dicha región.

De acuerdo con observaciones realizadas en la base de la quebrada (cauce), la acumulación de sedimentos cuaternarios eluviales, escombros y ceniza volcánica, constituye una cubierta sobre el cauce seco de la quebrada. No presenta evidencias recientes de escorrentía de agua. 
Geológicamente, está constituida por rocas del basamento de la costa, y tiene una profundidad de $35 \mathrm{~m}$ con respecto a la Panamericana. Su talud en el lado correspondiente a la carretera tiene una pendiente de 70 grados, con buzamiento hacia el oeste. Sobre su talud hay presencia de escombros no consolidados, colocados en el lugar cuando se construyó la carretera, por lo que cualquier movimiento lo hace inestable.

\section{Características de su nivel de base}

\section{Caracteristicas litológicas}

Como se explico anteriormente, está compuesta por rocas ígneas intrusivas altamente meteorizadas de granito rojo de Camaná, que son rocas sedimentarias con alto contenido de arena, arcillas y material fosilífero, los mismos que han contribuido a formar la base de la Quebrada del Toro (material eluvial).

\section{Características hidrológicas}

No existen huellas de escorrentía en las quebradas, por lo menos en las últimas décadas. Asimismo, en cuanto al nivel freático, se considera que la zona está libre de aguas subterráneas por la presencia de rocas ígneas (basamento cristalino), las cuales no presentan condiciones para la presencia de un acuífero.

\section{Caracteristicas meteorológicas}

De los factores meteorológicos, el más importante es la alta concentración de humedad en la zona, característica de la zona costera de nuestra región. En invierno, la humedad relativa puede llegar al $90 \%$, pero su promedio anual es de más del $50 \%$. En algunas épocas del año se producen neblinas, y la precipitación pluvial es escasa. Presenta marcada variación térmica entre el verano y el invierno.

\section{Características biológicas}

Tanto la flora y la fauna, que son escasas, son propias de una zona desértica. La acción del derrame de hidrocarburos con contenidos de sulfatos y metales pesados tiene la capacidad de dispersarse a lo largo de la quebrada, aunque ocasionando daños no significativos a la flora y fauna existentes, por las características rocosas y de aridez de la zona.

Flora. Entre las plantas xerófitas, se ha logrado identificar a las siguientes:

- Chilhua (Ambrosia fruticosa)

- Tabaquillo silvestre (Nicotinnae)

- Chire chire (Glenderia glutinosa)

- Malváceas (taraza)

- Cactáceas como el Corryo cactus peruvianus.

Fauna. Se observa la presencia de:

- Lagartijas (Microlophusperuvianus)

- Diversas aves como golondrinas (Pygochelidon cyanoleuca), palomas (Zenaida auriculata), lechuzas (Arenaria interpres), etc.

\section{Características socioeconómicas}

La Quebrada del Toro permite el paso de la carretera Panamericana, que tiene un ancho de $7,20 \mathrm{~cm}$ y se constituye como la principal vía de comunicación terrestre que conecta todos los pueblos de la costa peruana. Por lo tanto, soporta una carga vehicular intensa y de alto tonelaje.

\section{Análisis de la situación en la zona de impacto}

El granito rojo es una de las rocas más antiguas de la costa, y por haber estado bajo el mar y estar actualmente afectado por los fenómenos meteorológicos de la zona (70 \% de humedad relativa), se encuentra en un franco proceso de meteorización. En la zona de impacto se puede observar que el talud es de fácil desgranado, pro- 
ceso que en el sector puede alcanzar varios metros e incluso puede comprometer parte de la vía asfaltada en la Curva del Diablo.

Se ha observado que en el lugar se produce un esfuerzo de reptación lenta hacia la quebrada, lo que queda corroborado por una superposición de la capa asfáltica, en donde han sido cubiertos los ojos de gato que divide el asfalto. Existe un levantamiento del talud de corte de la carretera a la quebrada, e incluso se ha medido una diferencia de $6 \mathrm{~cm}$ como promedio de diferencia de altura en el sector medio de la pista. Este proceso de superposición tiene una longitud de $74 \mathrm{~m}$ aproximadamente, y es la única zona en toda la quebrada que presenta estas irregularidades.

En este sector, que corresponde a un corte de carretera, el material ha sido colocado en el talud del cauce de la quebrada. Tiene una gradiente muy alta (70 grados), y por lo tanto es inestable. Muy cerca del cauce, el cambio de talud es entre 50 y 60 grados de inclinación, y se observa la exposición del suelo natural, por lo que en dicha zona es más estable.

\section{Combustible diésel 2}

La biorremediación puede ser empleada para atacar contaminantes específicos del suelo, como por ejemplo en la degradación bacteriana de compuestos organoclorados o de hidrocarburos. Un tratamiento generalizado es la limpieza de derrames de petróleo por medio de la adición de fertilizantes con nitratos o sulfatos para estimular la reproducción de bacterias exógenas y de esa forma facilitar la descomposición del petróleo crudo.

El diesel 2, también conocido como ACMP (aceite combustible para motor), es un destilado medio obtenido de la destilación atmosférica del petróleo crudo. Su calidad de ignición se caracteriza por el Índice de Cetano o por el Número de Cetano.
EL ÍNDICE DE CETANO se calcula a partir de algunas propiedades de destilación y debe ser 45, como mínimo.

El NÚMERO DE CETANO es un indicador más preciso que el Índice de Cetano, y se calcula según el trabajo realizado por un motor bajo condiciones estándar. Está diseñado para utilizarse como combustible en motores diésel que operan bajo condiciones de alta exigencia y en altitudes por debajo de los $2000 \mathrm{~m}$ sobre el nivel del mar; también existe el diésel premium (bajo en azufre), especial para operar bajo condiciones de baja y mediana exigencia y en altitudes por encima de los $2000 \mathrm{~m}$ sobre el nivel del mar.

\section{Biorremediación}

Se define como biorremediación a cualquier proceso que utilice microorganismos, hongos, plantas o enzimas derivadas de ellos para retornar un medio ambiente alterado por contaminantes a su condición natural. La biorremediación consiste y se compone de etapas esenciales para su adecuada funcionalidad, desde el análisis de la línea de base, pasando por la remoción del material contaminado hasta el pretratamiento y disposición final. La biorremediación es la mejor alternativa, por ser ecológicamente amigable con el medio ambiente.

\section{Microorganismos eficientes}

Las bacterias utilizadas en esta tesis son llamadas microorganismos eficientes (EM). Provenientes del Japón y trabajan en una simbiosis compuesta por más de 80 tipos de microorganismos de origen natural, entre los que destacan tres:

- Bacterias acidolácticas.

- Bacterias fototrópicas.

- Levaduras. 
Los EM fueron descubiertos hace más de 25 años por el Dr. Teruo Higa, catedrático e investigador de la Facultad de Agronomía de la Universidad de Okinawa. Su primer propósito fue mejorar la calidad de los suelos y el rendimiento de los cultivos sin la utilización de agroquímicos dañinos al ambiente.

Actualmente, los EM son utilizados en más de 185 países con un rotundo éxito, en campos como:

- La agricultura intensiva.

- La elaboración de abonos orgánicos.

- La crianza y sanidad animal.

- Tratamiento de aguas residuales.

- La acuicultura.

- La eliminación de metales pesados.

- Los productos medicinales.

- Los productos de belleza.

\section{BACTERIAS ACIDOLÁCTICAS (Lactobacillus spp.)}

También conocidas por su nomenclatura oficial: ácido 2-hidroxi-propanoico o ácido $\alpha$-hidroxi-propanoico, son compuestos químicos que juega importantes roles en diversos procesos bioquímicos, como la fermentación láctica.

El ácido láctico es un quirómero, por lo que posee dos isómeros ópticos. Uno es el dextrógiro ácido D-(-)-láctico o d-ácido láctico (en este caso, el ácido (R)-láctico); el otro es el levógiro ácido $\mathrm{L}$-(+)-láctico o $\ell$-ácido láctico (en este caso, ácido ( $S$ )-láctico), que es el que tiene importancia biológica. La mezcla racémica (cantidades idénticas de estos isómeros) se llama $\mathrm{d}, \ell$ ácido láctico.

Las bacteria acidolácticas producen ácido láctico de azúcares y otros carbohidratos, producidos por las bacterias fototrópicas y levaduras. Por eso, algunas comidas y bebidas como el yogur y los encurtidos son hechas con bacterias acidolácticas desde tiempos remotos. Sin embargo, el ácido láctico es un compuesto esterilizante fuerte que suprime microorganismos dañinos y ayuda a la descomposición de materiales como la lignina y la celulosa, fermentándolos y removiendo efectos no deseables de la materia orgánica no descompuesta.

Las bacterias acidolácticas tienen la habilidad de suprimir enfermedades, incluyendo microorganismos como el fusarium, que aparecen en programas de cultivos continuos. En circunstancias normales, especies como el fusarium debilitan las plantas, exponiéndolas a enfermedades y plagas, como la de los nematodos.

El uso de bacterias acidolácticas reduce las poblaciones de nematodos y controla la propagación y dispersión de fusarium, gracias a lo cual induce un mejor ambiente para los cultivos.

Figura 2. Distribución espacial del ácido láctico

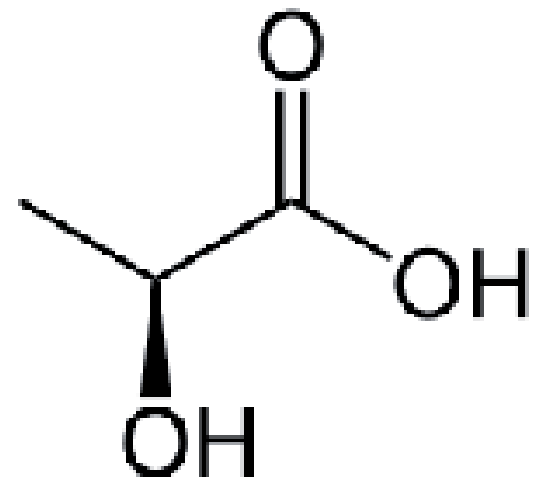

\section{BACTERIAS FOTOTRÓPICAS (Rhodopseudomonasspp.)}

Estas bacterias sintetizan sustancias útiles de secreciones de raíces, materia orgánica y gases dañinos (ácido sulfhídrico, por ejemplo) con el uso de luz solar y calor del suelo como fuentes de energía. Estas sustancias útiles incluyen aminoácidos, ácidos nucleicos, sustancias bioactivas y azúcares, los cuales promueven el crecimiento y desarrollo de la planta. 
Los metabolitos hechos por estos microorganismos son absorbidos directamente por las plantas y actúan como sustrato para el incremento poblacional de microorganismos benéficos. Por ejemplo, en la rizosfera, las micorrizas vesicular y arbuscular (VA) se incrementan gracias a la disponibilidad de compuestos nitrogenados (aminoácidos) que son secretados por las bacterias fototrópicas. En respuesta, las micorrizas VA incrementa la solubilidad de fosfatos en el suelo y por ello otorgan fósforo que no estaba disponible a las plantas. Las micorrizas VA también pueden coexistir con azobacter y rizobiums, incrementando la capacidad de las plantas para fijar nitrógeno de la atmósfera.

\section{LEVADURAS (Saccharomycetes spp.)}

Las levaduras sintetizan sustancias antimicrobiales, y otras requeridas por las plantas para su crecimiento, a partir de aminoácidos y azúcares secretados por las bacterias fototrópicas, materia orgánica y raíces de plantas.

Las sustancias bioactivas, como las hormonas y las enzimas producidas por las levaduras, promueven la división activa celular y radical. Estas secreciones también son sustratos útiles para los EM, como las bacterias acidolácticas y actinomycetes. Las diferentes especies de los EM (bacterias fototrópicas, acidolácticas y levaduras) tienen sus respectivas funciones. Sin embargo, las bacterias fototrópicas se pueden considerar como el núcleo de la actividad de los EM.

Las bacterias fototrópicas refuerzan las actividades de otros microorganismos. A este fenómeno se lo denomina "coexistencia y coprosperidad".

El aumento de poblaciones de EM en los suelos promueve el desarrollo de los microorganismos benéficos existentes en el suelo, ya que la microflora del suelo se torna abundante y, gracias a ello, el suelo desarrolla un sistema microbial bien balanceado. En este proceso, microbios específicos (especialmente los dañinos) son suprimidos, reduciéndose así especies microbiales del suelo que causan enfermedades. En contraste, en estos suelos desarrollados, los EM mantienen un proceso simbiótico con las raíces de las plantas junto a la rizosfera.

Las raíces de las plantas también secretan sustancias como carbohidratos, aminoácidos, ácidos orgánicos y enzimas activas. Los EM utilizan estas secreciones para su crecimiento. En el transcurso de este proceso, los EM también secretan y proveen aminoácidos, ácidos nucleicos y una gran variedad de vitaminas y hormonas a las plantas. Esto significa que los EM en la rizosfera coexisten con las plantas. Por ello, en suelos dominados por los EM, las plantas crecen excepcionalmente bien.

\section{Ventajas de la biorremediación}

- El material contaminado se podrá convertir en un abono orgánico enriquecido, con mayor cantidad de nutrientes, en especial nitrógeno.

- Mejorará la estructura y textura del suelo, haciendo más ligeros a los suelos arcillosos y más compactos a los arenosos.

- Mejorará la permeabilidad del suelo: drenaje y aireación.

- Aumentará la retención de agua en el suelo.

- Aumentará el poder tampón del suelo, reduciendo las oscilaciones de $\mathrm{pH}$.

- Aumentará la capacidad de intercambio catiónico (CIC) del suelo, con lo que aumentará la fertilidad.

- Favorecerá la aireación y oxigenación del suelo, provocando con ello una más intensa actividad radicular. 


\section{METODOLOGÍA}

\section{Análisis preliminar}

Las actividades de biorremediación se inician con un análisis preliminar para elaborar la línea de base ambiental de la zona del siniestro.

Para el análisis ambiental, se procedió de la siguiente forma: se realizó la visita inicial a la zona del derrame con el objetivo de tomar las primeras muestras de suelo para su posterior análisis (Anexo 1), se aplicó el test de percolación, y para establecer la metodología de trabajo a aplicar para la remoción del suelo contaminado, se procedió a determinar las características geológicas, geográficas y condiciones de estabilidad de las áreas, explicadas en el capítulo anterior.

Además de la observación de la fauna, se hizo un muestreo de la flora y se tomaron fotografías. Todos estos datos conformaron la línea de base ambiental, punto de partida para el Plan de Biorremediación de Suelos Contaminados por Diésel 2.

\section{Toma de muestras}

La toma de muestras de suelo contaminado por diésel se lleva a cabo para saber la concentración total de contaminantes por cantidad de tierra. De esta manera se podrá cuantificar la evolución del suelo a lo largo de todo el tratamiento.

Asimismo, se tomaron muestras de suelo no contaminado cercano al lugar del siniestro; esto con la finalidad de conocer la composición y tipo de suelo de la localidad y así poder interpretar la interacción suelo-contaminante.

\section{Test de percolación}

También conocido como test de permeabilidad, es una prueba que se emplea para determi- nar el grado de absorción del contaminante por el suelo. Consiste en cavar un agujero de aproximadamente $10 \mathrm{~cm}$ de profundidad y, usando una pipeta metrada, llenarlo con el mismo contaminante. Se mide el tiempo que tarde en descender el nivel del mismo.

\section{Angulo de inclinación del talud}

Para el análisis de los movimientos de inestabilidad de un talud o una ladera, es de primordial importancia el reconocimiento de los factores que actúan como desencadenantes. Su identificación permitirá, además, definir las medidas necesarias para evitarlos o corregirlos.

Suele admitirse que los factores o las causas que producen la inestabilidad de taludes o laderas no se presentan de manera aislada, sino que lo hacen normalmente combinados (excavaciones, lluvias, sismos, etc.).

La susceptibilidad de un terreno para deslizarse depende de los siguientes factores:

- Geología y tectónica.

- Geometría: altura e inclinación.

- Sobrecargas puntuales.

- Cambios en el contenido del suelo.

- Meteorización.

- Sacudidas sísmicas, voladuras o vibraciones.

\section{Trabajo de campo}

\section{Remoción manual}

El tramo del terreno afectado, correspondiente a los primeros $15 \mathrm{~m}$ desde el borde de la carretera hacia la base de la quebrada, presenta un ángulo de 70 grados, lo que lo hace muy inestable. Esto motivó que para los trabajos en esta área se considerara la remoción manual, conservando de esta forma las características geomorfológicas del lugar.

Para el proceso de remoción manual se con- 
trataron obreros que removieron la capa del suelo contaminada por hidrocarburos, que en promedio, y según el test de percolación, fue de 8 $\mathrm{cm}$ de espesor.

Se tomó en cuenta una metodología de trabajo que se detalla a continuación:

- Charlas de inducción de seguridad al personal. En estas charlas de seguridad se indicaron las normas básicas de prevención de riesgos, con la finalidad de evitar accidentes laborales y de desempeñar en forma adecuada el trabajo. Asimismo, se les dio a conocer los riesgos a los que estarían expuestos durante la ejecución del proyecto.

- Entrega de equipo de protección personal (EPP). Después de las charlas diarias de seguridad, se hacía entrega a cada uno de los obreros del equipo de protección personal. Adicionalmente, se elaboró un análisis de riesgo operacional (Anexo 3), de acuerdo al cual se determinó el equipo necesario para el desarrollo de las actividades.

- Armado de bríos pircados. Se tomaron las recomendaciones del estudio geológico y se armaron bríos pircados en la zona de remoción del material contaminado, como medida preventiva para la estabilidad del talud y seguridad de la carpeta asfáltica.

\section{Remoción con maquinaria pesada}

- Apertura de rutas de acceso. Fue necesaria la apertura de una ruta de acceso de $1,4 \mathrm{~km}$ aproximadamente para permitir el ingreso de la maquinaria pesada a la zona de derrame. En esta parte del trabajo, intervino un cargador frontal, el cual abrió el camino para el ingreso de los volquetes que transportarían el material hasta la zona de tratamiento.

- Retiro del material con maquinaria pesada. La remoción con maquinaria pesada se realizó en dos, etapas debido a la geología del terreno. La primera fue la remoción del material contaminado depositado en la zona adyacente a la base de la quebrada. Esta parte no fue perturbada ya que se abrió una vía de acceso de $8 \mathrm{~m}^{2}$, por la que los obreros descargaron la tierra contaminada para ponerla al alcance de la pala del cargador frontal y este a su vez la depositara en los volquetes.

La segunda etapa se realizó en la base de la quebrada, donde se removió tierra hasta una profundidad de $50 \mathrm{~cm}$, por ser este el nivel de percolación alcanzado por el diésel 2.

- Traslado a la zona de tratamiento. El traslado se llevó a cabo por dos volquetes de doble corona, que eran los únicos capaces de poder transitar por la vía de acceso abierta.

- Aplicación de microorganismos en la zona afectada. Debido a la inestabilidad, era imposible la remoción de las grandes rocas, puesto que realizaban la función de contención de la carpeta asfáltica, por lo que el material contaminante impregnado sobre ellas será removido con la ayuda de microorganismos.

\section{Tratamiento de biorremediación}

- Adecuación de la zona de tratamiento. La zona seleccionada fue un terreno de $750 \mathrm{~m}^{2}$ totalmente cercado con un suelo franco arenoso y sin población cercana. Se realizó una nivelación del suelo para darle una pendiente de 10 grados de este a oeste.

- Impermeabilización del área de trabajo. Se realizó la impermeabilización del suelo, recubriendo el mismo con una capa de $20 \mathrm{~cm}$ de arcilla, la cual fue compactada por un tractor. Además de esto, se colocaron las pilas en un polímero de alta densidad para evitar posibles lixiviados, los cuales, según el tratamiento de biorremediación, deberían ser inexistentes.

- Preparación de las pilas para la biorremediación. Las dimensiones de las pilas para la biorremediación influyen en la aireación y temperatura, y por lo tanto, en la transformación adecuada del material orgánico. Las dimensiones de las pilas están estrechamente relacionadas con los parámetros climatológi- 
cos de la zona en la que se está trabajando.

Para este tratamiento se han definido las siguientes dimensiones:

Altura: $1,00 \mathrm{~m}$

Ancho: $1,50 \mathrm{~m}$

Largo: $10,00 \mathrm{~m}$

Figura 3. Vista y medidas de la pila
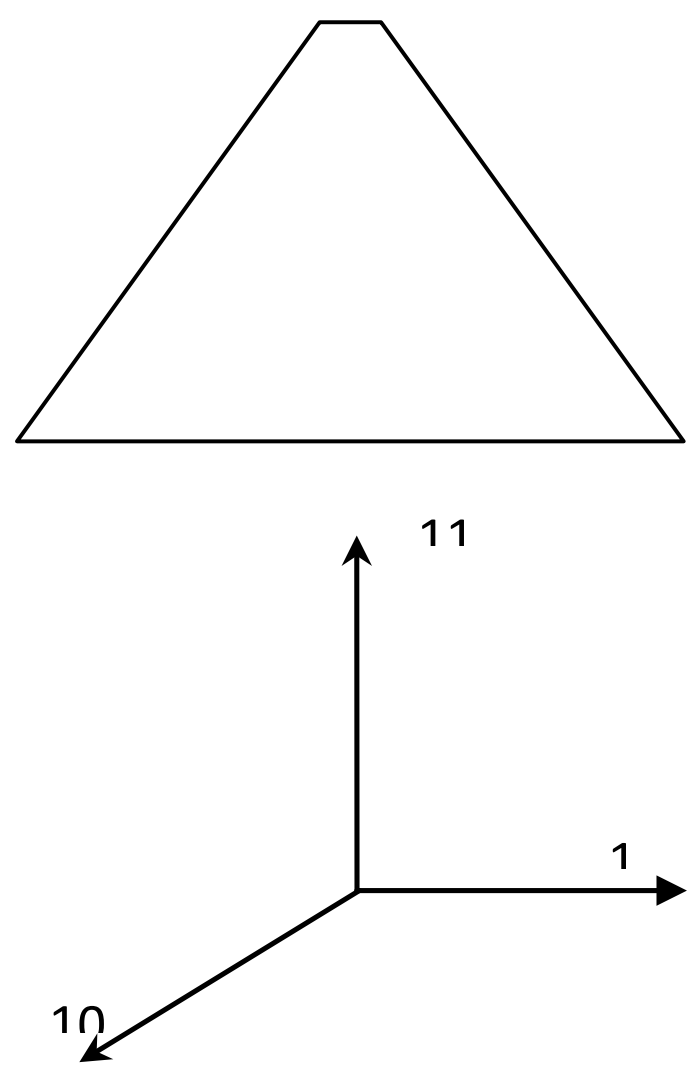

- Activación de los microorganismos. Los microorganismos eficientes (EM) se encuentran en estado de latencia, por lo que se necesita realizar su activación 96 horas antes de su primera aplicación.

- Aplicación y aireación. Después de la activación de las bacterias, se procedió a realizar la incorporación de los microorganismos a la tierra contaminada por derrame de hidrocarburos diésel 2, la que se colocó previamente en pilas, con lo cual se da inicio al tratamiento de biorremediación.

- Uso final del material contaminado. Después que el material perdió todas las características contaminantes del hidrocarburo, se hizo entrega del mismo a la municipalidad provincial de Camaná, la que reutilizará este material en los parques y jardines para aprovechar su alto contenido de nutrientes obtenidos por la actividad de las bacterias.

\section{ANÁLISIS DE RESULTADOS}

Como se muestra en los resultados de laboratorio (Anexo 1), y según el cronograma (Anexo 5), se realizaron todas las aplicaciones de microorganismos a la tierra contaminada, con lo que se obtuvieron muy buenos resultados.

Como se puede observar en el gráfico 1, la concentración de THP inicial fue de 234 $508 \mathrm{mg} / \mathrm{kg}$, pero en las primeras aplicaciones

Cuadro 3. Concentración de hidrocarburos totales en el suelo

\begin{tabular}{|c|c|c|c|}
\hline$N^{\circ}$ de análisis & Fecha & Unidades & Concentración \\
\hline 1er. análisis & $29 / 05 / 2009$ & $\mathrm{mg} / \mathrm{kg}$ & 234508,00 \\
\hline 2do. análisis & $03 / 06 / 2009$ & $\mathrm{mg} / \mathrm{kg}$ & 36756,78 \\
\hline 3er. análisis & $20 / 17 / 2009$ & $\mathrm{mg} / \mathrm{kg}$ & 25520,47 \\
\hline 4to. análisis & $24 / 09 / 2009$ & $\mathrm{mg} / \mathrm{kg}$ & 6981,15 \\
\hline
\end{tabular}


Grafico 1. Concentración de hidrocarburos totales en el suelo

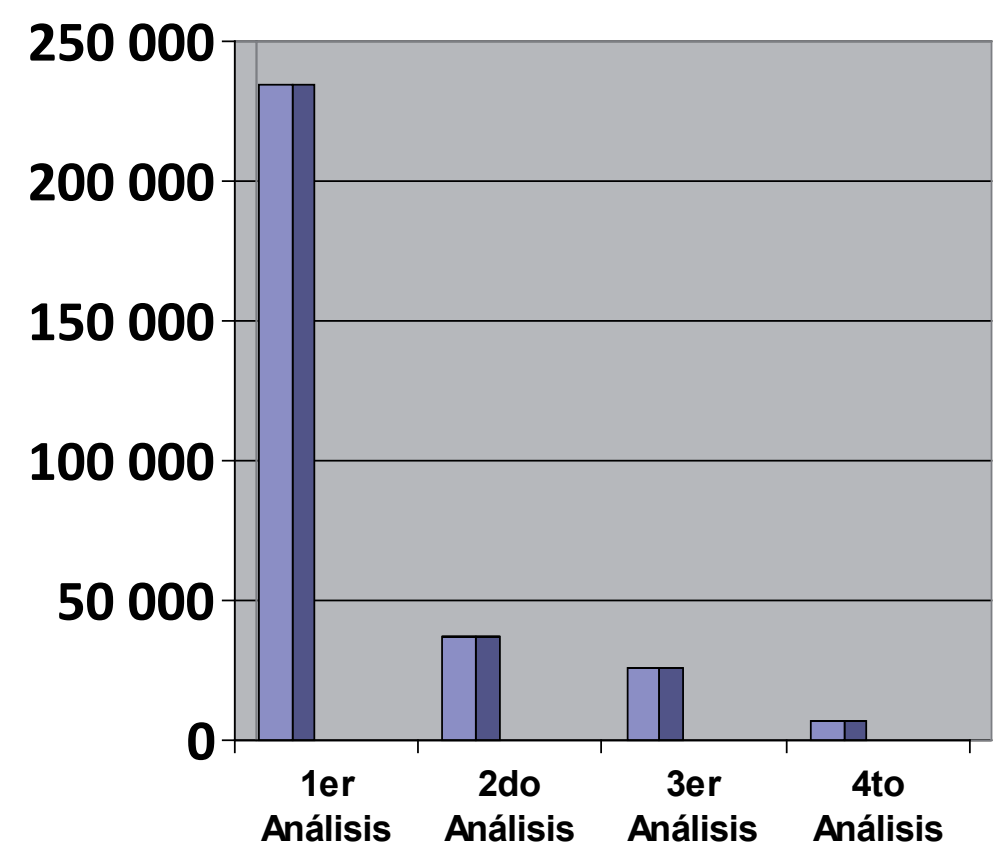

la concentración bajo considerablemente a 36 756,78, ya que el clima (temperatura y humedad) favoreció a la dinámica bacteriana.

Se observa que a partir del segundo análisis, la concentración de THP disminuye muy poco, ya que las condiciones meteorológicas cambiaron en la zona de tratamiento, es decir, las temperaturas descendieron y la humedad aumentó, dificultándose la actividad de las bacterias y demorando más el proceso de consumo de materia orgánica.

$\mathrm{Al}$ conocer los resultados del cuarto análisis, se observó que la concentración de hidrocarburos estaban por debajo de la norma referencial (Anexo 4), ya que no existe una norma peruana que regule este tipo de contaminación.

Se tomó como norma referencial la norma canadiense, ya que las otras normas (mexicana, holandesa y boliviana) son tomadas en cuenta cuando la tierra va a tener contacto directo con las personas. En el caso de la norma canadiense, se aplica a tierra que va a ser utilizada en cultivos o en cualquier otro fin parecido.

\section{CONCLUSIONES}

- Los accidentes vehiculares en las carreteras, especialmente aquellos en los que están involucrados vehículos de gran tonelaje, se están volviendo más frecuentes y con consecuencias más desastrosas. Se conoce, por antecedentes, que estos desenlaces no dependen solamente de un factor, sino que a menudo son varios los factores que terminan desencadenando el siniestro. Los más comunes son la imprudencia o inexperiencia del conductor, el exceso de velocidad, el mal estado de las carreteras y las condiciones climatológicas.

- Los suelos contaminados con hidrocarburos, especialmente, con combustible diésel 2, pueden ser remediados utilizando técnicas totalmente amigables con el medio ambiente, 
de modo que pueden ser rehabilitados para un uso agrícola o para la elaboración de abono orgánico.

- La biorremediación con EM es mucho más eficaz que los tratamientos habituales, los cuales consistían básicamente en el paleo del material para acelerar la volatilización del hidrocarburo, generando así gases nocivos para el medio ambiente. Otra forma de eliminar este material considerado peligroso por la presencia de hidrocarburos es encargárselo a una empresa prestadora de servicios para su disposición en un relleno de seguridad, lo cual resulta muy caro y muy tedioso.

- Los EMson un producto innovador, obtenido de la misma naturaleza, con un sinfín de usos en los campos ambiental, agrícola y ganadero, y se van a convertir sin duda en un ícono de la explotación sostenible de recursos naturales.

\section{RECOMENDACIONES}

- Fortalecer la tierra tratada, agregándole estiércol de animales con alto contenido de nitrógeno, lo que impedirá la muerte bacteriana por falta de nutrientes y por el contrario mejorará la textura de la tierra, haciéndola idónea para el cultivo.

- Con el fin de no generar un impacto negativo y mantener un orden en la topografía y el paisaje de la zona del accidente, se debe cubrir el terreno con una capa de tierra nueva de similares características a la extraída. En tal sentido, se recomienda hacer inspecciones oculares hasta que la nueva capa de tierra se afiance y no haya peligro de derrumbes.

\section{REFERENCIAS BIBLIOGRÁFICAS}

1. EM Research Organization Inc. Official Site of Dr. Teruo Higa's EM Technology. http://www.emrojapan.com.

2. Centro de Información Química para
Emergencias (CIQUIME). 2004. Guia Naranjade Respuesta en Caso de Emergencias. Buenos Aires, Argentina. C1406GSS.

3. Consejo Canadiense de Ministros del Ambiente. 1993. Manual de guias sobre muestreo, análisis y manejo de datos para sitios contaminados. Volumen 1: Informe Principal; Volumen 2: Resúmenes de métodos analíticos. Informe CCME EPCNCS62E. Ambiente Canadá. Ottawa, Ontario.

4. US EPA. 1991. Descripción y muestreo de suelos contaminados. Informe EPA/625/12$91 / 002$. Centro para la Información de Investigación Ambiental. Cincinnati, Ohio.

5. Ministerio de Energía y Minas. Subsector Hidrocarburos, 2000. Restauración de suelos en instalaciones de refinación y producción petrolera. Lima, Perú.

6. Sociedad Nacional de Minería, Petróleo y Energía(SNMPE).2009. Informe Quincenal de la SNMPE sobre Hidrocarburos. http:// www.snmpe.org.pe/repositorioaps/0/0/ jer/ininf_infquinchidro/EEES-IQ-442006-JR.pdf. Lima, Perú.

7. Mac Cormack, W. P. 1999. Selección, caracterización y evaluación del potencial biotecnológico de bacterias sicrotróficas degradadoras de hidrocarburos. Ph. D. thesis, University of Buenos Aires, 192 pp.

8. Collerman, E., 1997. "Uses of bacteria in bioremediation". In SHEENAN, D., ed. Bioremediation protocols. New Jersey, Humana Press, 3-22.

9. Cunningham, C. J. y Philp, J. C., 2000. Comparison of bioaugmentation and biostimulation in ex situ treatment of diesel contaminated soil. Land Contamination \& Reclamation, 8, 261-269.

10. Ruberto, Lucas; Vásquez, Susana; Lo Balbo, Alfredo; Mac Cormack, Walter. Biorremediacion de suelos contaminados con hidrocarburos utilizando bacterias antárticas sicrotolerantes. http://www. 
dna.gov.ar/CIENCIA/SANTAR04/

CD/PDF/206BH.PDF. Buenos Aires, Argentina.

11. Lagrega M.D., Buckingham P.L., Evans. Environmental Resources Management (2001). Hazardous waste management. McGraw-Hill.

12. Mata-Sandoval J.C., Korns, J. and Torrents A. (2000) "The influence of surfactants and biosurfactants on the bioavailability of hidrophobic organic pollutants in subsurface environments". Rev. Int. Contam. Ambient. 16(4): 193-203.

13. Propiedades físicas y químicas de los hidrocarburos. http://www.gas-servei. $\mathrm{com} /$ docs/Propiedades\%20fisicas $\% 20$ y\%20medioambientales.pdf. 